\title{
Association Study of Suicidal Behavior and Affective Disorders with a Genetic Polymorphism in ABCG1, a Positional Candidate on Chromosome 21 q22.3
}

\author{
D. Rujescu a I. Giegling a N. Dahmen ${ }^{b} \quad$ A. Szegedi ${ }^{b} \quad$ I. Anghelescu ${ }^{b}$ \\ A. Gietl ${ }^{a}$ M. Schäfer ${ }^{a} \quad$ F. Müller-Siecheneder ${ }^{a} \quad$ B. Bondy ${ }^{a}$ H.-J. Möller ${ }^{a}$ \\ a Department of Psychiatry, Ludwig-Maximilians-University, Munich, and bepartment of Psychiatry, \\ Johannes-Gutenberg-University, Mainz, Germany
}

\section{Key Words}

ABCG1 - Tryptophan · Affective disorder · Suicide attempt · Association study · Genetic polymorphism • Positional candidate

\begin{abstract}
The gene that codes for the $A B C$ transporter $A B C G 1$ is located in a chromosomal susceptibility region (21q22.3) for affective disorders. Genetic variations in ABCG1 have been associated with affective disorders in Japanese males. In this study, we investigated the distribution of a G2457A polymorphism in patients with affective disorders, suicide attempters with various psychiatric diagnoses and healthy subjects. We initially found a trend towards a modest association with affective disorders in males ( $p=0.046$ for allele frequencies and $p=0.046$ for AA versus $G G$ ). We conducted a replication study with independent patients and controls. There was no association with affective disorders, either in the replication or in the combined group. Furthermore, we found no association with suicidal behavior. These findings do not support the hypothesis that ABCG1 is a susceptibility gene for affective disorders or suicidal behavior.
\end{abstract}

Copyright (@) 2000 S. Karger AG, Basel

\section{Introduction}

The ABC transporter homologous to Drosophila white gene $(\mathrm{ABCG} 1)$ is a member of the ATP-binding cassette (ABC) transporter superfamily of transmembrane permeases with highest levels of expression in brain, spleen and lung. The gene is located in a chromosomal region (21q22.3) that has been linked to affective disorders by several investigators [1]. Hence, the ABCG1 transporter gene might represent a good positional candidate for affective disorders. Since 1969, when Lapin and Oxenkrug [2] formulated the serotonin hypothesis of depression, a large body of evidence has been gathered to indicate that altered serotonin metabolism might be involved in the pathobiochemistry of affective disorders [3]. Although not yet demonstrated in humans, the gene product of ABCG1 is involved in the transport of tryptophan, the precursor of serotonin, in Drosophila [4]. Moreover, Nakamura et al. [5] found an association of a G2457A polymorphism in the ABCG1 gene with mood disorders in males. These lines of evidence support the notion that the ABCG1 gene might indeed be a susceptibility gene in affective disorders. Suicidal behavior has been widely related to altered serotonergic transmission [3,6]. There is a remarkable association between low concentrations of

\begin{tabular}{ll}
\hline KARGER & ( ) 2000 S. Karger AG, Basel \\
Fax +4161306 1234 34 X $100 / 0425-0022 \$ 17.50 / 0$ \\
$\begin{array}{l}\text { E-Mail karger@karger.ch } \\
\text { www.karger.com }\end{array}$ & $\begin{array}{l}\text { Accessible online at: } \\
\text { www.karger.com/journals/nps }\end{array}$
\end{tabular}

\footnotetext{
Dan Rujescu, MD

Molecular Neurobiology, Department of Psychiatry, Ludwig-Maximilians-University Nussbaumstrasse 7, D-80336 Munich (Germany)

Tel. +49 8951605756 (office), +49 8951603371 (lab), Fax +49 8951605779

E-Mail Dan.Rujescu@psy.med.uni-muenchen.de
} 
5-hydroxyindoleacetic acid in the cerebrospinal fluid and suicidal behavior within a wide range of diagnoses [7]. With regard to suicidal behavior, twin and adoption studies show a clear genetic contribution [8]. No linkage studies have been published to date, but several association studies indicate that variations in serotonergic genes might be associated with suicide attempts $[9,10]$. Although the molecular genetic findings are somehow inconsistent, only a few studies were designed to address this question directly. In order to test the hypothesis that ABCG1 is a susceptibility gene for affective disorders and suicidal behavior, we performed an association study with a G2457A single nucleotide polymorphism at position 2457 in the 3'-UTR of the ABCG1 gene in two independent populations of patients suffering from affective disorders, and one population of patients with various psychiatric diagnoses who had made a documented suicide attempt.

\section{Materials and Methods}

\section{Psychiatric Patients}

Two groups of patients consisted of 18- to 65-year-old Caucasian inpatients, hospitalized in the Department of Psychiatry, LudwigMaximilians-University, Munich, Germany. One group had a current or past history of suicide attempts and various psychiatric disorders ( $\mathrm{n}=70 ; 26$ males, 44 females), whereas another group had affective disorders ( $\mathrm{n}=52 ; 17$ males, 35 females). In the latter group, 42 patients were diagnosed with unipolar major depression (14 males, 28 females) and 10 patients with bipolar disorder ( 3 males, 7 females). The diagnosis was established by the Structured Clinical Interview for DSM-IV (SCID I and SCID II).

The replication sample consisted of 18- to 65-year-old Caucasian outpatients with major depression according to DSM-IV criteria $(\mathrm{n}=$ 104; 25 males, 79 females) recruited from the Department of Psychiatry, Johannes-Gutenberg-University, Mainz, Germany. The diagnosis was established by the Mini International Neuropsychiatric Interview [11].

Exclusion criteria for all groups included any serious medical condition, mood disorders due to a general medical condition or substance abuse, dementia, and also schizophrenia and related psychotic disorders.

\section{Control Subjects}

We randomly selected 18- to 65-year-old Caucasians from the general population of Munich and contacted them by mail. Subjects who responded were first screened by phone. They subsequently filled out a detailed medical history form both for themselves and their relatives. Psychiatric disorders of the subjects were excluded by SCID I and SCID II, and a psychiatric diagnosis in first- and seconddegree relatives was excluded using the Family History Assessment Module. Ninety-seven healthy control subjects (48 males, 49 females) without relevant somatic and with no psychiatric disorder were included.
For the replication study, 18- to 65-year-old Caucasians ( $\mathrm{n}=92$; 65 males, 27 females) were recruited by the Department of Psychiatry, Johannes-Gutenberg-University, Mainz, Germany, as healthy controls.

After written informed consent had been obtained from all subjects, blood samples were collected and the distribution of a genetic polymorphis in the ABCG1 gene was examined.

\section{Genotyping}

Genomic DNA was prepared from $10 \mathrm{ml}$ blood using the Quiagen Maxi DNA Extraction Kit. In order to assess allele and genotype frequency of the $\mathrm{A} 2457 \mathrm{G}$ transversion polymorphism in the $3^{\prime}$ untranslated region of $\mathrm{ABCG} 1, \mathrm{PCR}$ was performed with primer pair HDW-1 (5'-ACA GCT GGT GAT GAG AGG CT-3') and HDW-r (5'-AGA TGG TGT CCA CGT CTT CC-3'). The 50- $\mu$ l reactions contained 50 ng genomic DNA, $0.4 \mathrm{~m} M$ dNTPs, $50 \mathrm{~m} M \mathrm{KCl}$, $20 \mathrm{~m} M$ Tris- $\mathrm{HCl}$ ( $\mathrm{pH} 8.4$ ), $1.5 \mathrm{mM} \mathrm{MgCl}_{2}, 0.3 \mu M$ of each primer, and $1 \mathrm{U}$ Taq polymerase (Life Technologies). Following an initial denaturation step at $95^{\circ} \mathrm{C}$ for $3 \mathrm{~min}$. DNA was amplified in 35 cycles of PCR $\left(94{ }^{\circ} \mathrm{C}\right.$ for $30 \mathrm{~s}, 56^{\circ} \mathrm{C}$ for $30 \mathrm{~s}, 72{ }^{\circ} \mathrm{C}$ for $\left.1 \mathrm{~min}\right)$. The final extension step was $72{ }^{\circ} \mathrm{C}$ for $5 \mathrm{~min} ; 30 \mu \mathrm{l}$ of the PCR product were digested with $5 \mathrm{U}$ of $\mathrm{HhaI}$ (New England Biolabs), analyzed by gel electrophoresis in a $2 \%$ agarose gel containing ethidium bromide and visualized under UV light. When guanine is present at position 2457 in the 3'-UTR (pos. 104 of the PCR product), digestion results in two fragments of $104 \mathrm{bp}$ and $321 \mathrm{bp}$, whereas the absence of the HhaI recognition site leaves the 425 -bp PCR product intact.

\section{Statistical Analysis}

$\chi^{2}$ Tests were performed to compare allele and genotype frequencies. Values of $\mathrm{p}<0.05$ were considered significant, while $\mathrm{p}<0.1$ was viewed as indicating a trend.

\section{Results}

The distribution of genotype and allele frequencies of the polymorphism in the ABCG1 gene in healthy controls, patients with affective disorders and suicide attempters is shown in table 1 . The genotypic distribution was in Hardy-Weinberg equilibrium (total controls: $\chi^{2}=$ 0.332, $\mathrm{p}=0.847$; male controls: $\chi^{2}=0.167, \mathrm{p}=0.920$; female controls: $\chi^{2}=0.165, p=0.921$ ). In our first sample of patients with affective disorders, we found a trend towards higher frequencies of the $\mathrm{G}$ allele and GG genotype in males $(p=0.046$ for allele frequencies, $p=0.113$ for genotype frequencies and $\mathrm{p}=0.046$ for $\mathrm{AA}$ versus GG), but not in females ( $p=0.714$ for allele and $p=0.577$ for genotype frequencies) or in the total sample ( $p=0.128$ for allele and $p=0.216$ for genotype frequencies). In order to replicate these findings, we examined the distribution of the polymorphism in an independent sample consisting of patients with major depression in comparison to a further sample of locally recruited healthy controls. In this analysis, there was no association of any of the genetic 
Table 1. Genotype and allele distributions for the A2457G polymorphism in the ABCG1 gene among patients with mood disorders, suicide attempters and healthy controls

\begin{tabular}{|c|c|c|c|c|c|c|c|c|c|c|c|}
\hline \multirow[t]{3}{*}{ Subjects } & \multirow[t]{3}{*}{$\mathrm{n}$} & \multicolumn{6}{|c|}{ Genotype distribution } & \multicolumn{4}{|c|}{ Allele frequency } \\
\hline & & \multicolumn{2}{|c|}{$\mathrm{A} / \mathrm{A}$} & \multicolumn{2}{|c|}{$\mathrm{A} / \mathrm{G}$} & \multicolumn{2}{|c|}{$\mathrm{G} / \mathrm{G}$} & \multicolumn{2}{|l|}{ A } & \multicolumn{2}{|l|}{ G } \\
\hline & & $\mathrm{n}$ & $\%$ & $\mathrm{n}$ & $\%$ & $\mathrm{n}$ & $\%$ & $\mathrm{n}$ & $\%$ & $\mathrm{n}$ & $\%$ \\
\hline Healthy controls, original sample & 97 & 24 & 24.7 & 44 & 45.4 & 29 & 29.9 & 92 & 47.4 & 102 & 52.6 \\
\hline \multirow{2}{*}{$\begin{array}{l}\text { Total Males } \\
\text { Females }\end{array}$} & 48 & 12 & 25.0 & 22 & 45.8 & 14 & 29.2 & 46 & 47.9 & 50 & 52.1 \\
\hline & 49 & 12 & 24.5 & 22 & 44.9 & 15 & 30.6 & 46 & 46.9 & 52 & 53.1 \\
\hline \multirow{3}{*}{$\begin{array}{l}\text { Healthy controls, replication sample } \\
\text { Total Males } \\
\quad \text { Females }\end{array}$} & 92 & 15 & 16.3 & 51 & 55.4 & 26 & 28.3 & 81 & 44.0 & 103 & 56.0 \\
\hline & 65 & 12 & 18.5 & 38 & 58.5 & 15 & 23.1 & 62 & 47.7 & 68 & 52.3 \\
\hline & 27 & 3 & 11.1 & 13 & 48.2 & 11 & 40.7 & 19 & 35.2 & 35 & 64.8 \\
\hline \multirow{3}{*}{$\begin{array}{l}\text { Mood disorders, original sample } \\
\text { Total Males } \\
\quad \text { Females }\end{array}$} & 52 & 10 & 19.2 & 19 & 36.5 & 23 & 44.2 & 39 & 37.5 & 65 & 62.5 \\
\hline & 17 & 1 & 5.9 & 7 & 41.2 & 9 & 52.9 & 9 & 26.5 & 25 & 73.5 \\
\hline & 35 & 9 & 25.7 & 12 & 34.3 & 14 & 40.0 & 30 & 42.9 & 40 & 57.1 \\
\hline \multirow{3}{*}{$\begin{array}{l}\text { Mood disorders, replication sample } \\
\text { Total Males } \\
\quad \text { Females }\end{array}$} & 104 & 24 & 23.1 & 51 & 49.0 & 29 & 27.9 & 99 & 47.6 & 109 & 52.4 \\
\hline & 25 & 7 & 28.0 & 12 & 48.0 & 6 & 24.0 & 26 & 52.0 & 24 & 48.0 \\
\hline & 79 & 17 & 21.5 & 39 & 49.4 & 23 & 29.1 & 73 & 46.2 & 85 & 53.8 \\
\hline \multirow{3}{*}{$\begin{array}{l}\text { Suicide attempters } \\
\text { Total Males } \\
\text { Females }\end{array}$} & 70 & 18 & 25.7 & 28 & 40.0 & 24 & 34.3 & 64 & 45.7 & 76 & 54.3 \\
\hline & 26 & 6 & 23.1 & 9 & 34.6 & 11 & 42.3 & 21 & 40.4 & 31 & 59.6 \\
\hline & 44 & 12 & 27.3 & 19 & 43.2 & 13 & 29.5 & 43 & 48.9 & 45 & 51.1 \\
\hline
\end{tabular}

variants with major depression in males ( $p=0.726$ for allele and $\mathrm{p}=0.565$ for genotype frequencies), females ( $p=0.210$ for allele and $p=0.366$ for genotype frequencies) or in the total sample ( $p=0.336$ for allele and $p=$ 0.394 for genotype frequencies). When combining both groups of patients with affective disorders and comparing them to the pooled data of healthy controls, there was no association of any variant of the G2457A polymorphism in the ABCG1 gene with affective disorders (both genders: $p=0.998$ for allele and $p=0.692$ for genotype frequencies; males: $p=0.352$ for allele and $p=0.482$ for genotype frequencies; females: $p=0.896$ for allele and $p=$ 0.630 for genotype frequencies). Moreover, there was no association of any variant of the polymorphism with suicidal behavior ( $p=0.844$ for allele and $p=1.0$ for genotype frequencies).

\section{Discussion}

In contrast to the previous report by Nakamura et al. [5], who found an association of the A allele and AA genotype of the G2457A polymorphism in the ABCG1 gene with affective disorders in males, the $\mathrm{G}$ allele and GG genotype frequencies tended to be higher in our first group of males with affective disorders. In order to avoid false-positive results, we attempted to reproduce these findings in replication samples. In these samples, there was no association with major depression. Moreover, allele and genotype frequencies did not differ between cases and controls when data from both studies were combined. These findings might suggest that variations in the ABCG1 gene do not contribute to the genetic susceptibility to affective disorders. Affective disorders are currently conceptualized as etiologically heterogeneous, with individuals carrying probably different, although partially overlapping, sets of susceptibility genes. It is possible that the affective disorder groups used in this study do not share identical susceptibility genes. The initial group consists of inpatients with a severer course, and probably lifetime course of the illness, in comparison with the replication sample consisting of outpatients with a more restricted range of affective symptoms (i.e. unipolar depression in most of the cases). Replication studies in larger populations of patients are necessary in order to clarify the role of ABCG1 in affective disorders. It is also possible that another gene located in the chromosomal region, 21q22.3, may turn out to be involved in the genetic vul- 
nerability to mood disorders. This is the first study to investigate the role of the ABCG1 transporter in suicidal behavior. Our results do not provide evidence that ABCG1 transporter gene contributes to the genetic susceptibility for suicidal behavior.

\section{Acknowledgments}

D.R. is kindly supported by the Vada and Theodore Stanley Foundation. We are grateful to both the patients and the healthy volunteers who participated in this study.

\section{References}

1 Gurling H: Chromosome 21 workshop. Psychiatr Genet 1998;8:109-113.

2 Lapin IP, Oxenkrug GF: Intensification of the central serotoninergic processes as a possible determinant of the thymoleptic effect. Lancet 1969;i:132-6.

3 Mann JJ: Role of the serotonergic system in the pathogenesis of major depression and suicidal behavior. Neuropsychopharmacology 1999;21 (suppl 2):99S-105S.

4 Ewart GD, Cannell D, Cox GB, Howells AJ: Mutational analysis of the traffic ATPase (ABC) transporters involved in uptake of eye pigment precursors in Drosophila melanogaster. Implications for structure-function relationships. J Biol Chem 1994;269:1037010377.
5 Nakamura M, Ueno S, Sano A, Tanabe H: Polymorphisms of the human homologue of the Drosophila white gene are associated with mood and panic disorders. Mol Psychiatry 1999;4:155-162.

6 Mann JJ: The neurobiology of suicide. Nat Med 1998;4:25-30.

7 Asberg M: Neurotransmitters and suicidal behavior. The evidence from cerebrospinal fluid studies. Ann N Y Acad Sci 1997;836:158-181.

8 Roy A, Rylander G, Sarchiapone M: Genetics of suicides. Family studies and molecular genetics. Ann N Y Acad Sci 1997;836:135-157.
9 Nielsen DA, Virkkunen M, Lappalainen J, Eggert M, Brown GL, Long JC, Goldman D, Linnoila $\mathrm{M}$ : A tryptophan hydroxylase gene marker for suicidality and alcoholism. Arch Gen Psychiatry. 1998;55:593-602.

10 Mann JJ, Malone KM, Nielsen DA, Goldman D, Erdos J, Gelernter J: Possible association of a polymorphism of the tryptophan hydroxylase gene with suicidal behavior in depressed patients. Am J Psychiatry 1997;154:1451-1453.

11 Sheehan DV, Lecrubier Y, Sheehan KH, et al: The MINI International Neuropsychiatric Interview (MINI): The development of a structured diagnostic psychiatric interview for DSM-IV and ICD-10. J Clin Psychiatry 1998; 59(suppl 20): S22-S33, quiz 34-57. 